Research Article

\title{
Pharmacokinetics and Tissue Distribution of Combined Triptolide and Paeoniflorin Regimen for Percutaneous Administration in Rats Assessed by Liquid Chromatography-Tandem Mass Spectrometry
}

\author{
Yong-mei Guan $\mathbb{D}^{1},{ }^{1}$ Qian Shen $\mathbb{D}^{1},{ }^{1}$ Liang-fei He ${ }^{\mathbb{D}},{ }^{1}$ Li-mei Chen $\mathbb{D}^{1},{ }^{1,2}$ Zhenzhong Zang $\mathbb{D}^{1}$, \\ Lili Liu $\mathbb{D}^{1},{ }^{1}$ Wei-feng Zhu $\mathbb{D}^{1},{ }^{1}$ Chen Li-hua $\mathbb{D}^{1},{ }^{1}$ and Hong-ning Liu $\mathbb{D}^{1}$ \\ ${ }^{1}$ Jiangxi University of Chinese Medicine, Nanchang, Jiangxi, China \\ ${ }^{2}$ The Affiliated Hospital of Jiangxi University of TCM, Nanchang, Jiangxi, China
}

Correspondence should be addressed to Li-mei Chen; 201891800002@jxutcm.edu.cn and Zhenzhong Zang; 20194015@ jxutcm.edu.cn

Received 2 September 2020; Revised 22 April 2021; Accepted 24 June 2021; Published 8 July 2021

Academic Editor: Dinesh Dhamecha

Copyright (c) 2021 Yong-mei Guan et al. This is an open access article distributed under the Creative Commons Attribution License, which permits unrestricted use, distribution, and reproduction in any medium, provided the original work is properly cited.

\begin{abstract}
Triptolide (TP) has shown potential in rheumatoid arthritis (RA) treatment, but the narrow therapeutic window limits its clinical application. In clinical practice, the compatibility of Tripterygium wilfordii and Paeonia lactiflora is often used to attenuate the toxicity of TP, but its compatibility mechanism has not been fully elucidated. The aim of this study was to investigate the pharmacokinetics and tissue distribution of a combined regimen of TP and paeoniflorin (PF) after transdermal administration in male and female Sprague Dawley (SD) rats via a rapid and sensitive liquid chromatography-tandem mass spectrometry (LC-MS/MS) method. The results showed that after percutaneous administration of TP and PF, there was no significant difference in AUC $(0-t)$ (area under the curve) of TP, the peak concentration decreased by $58.17 \%$, and the peak time was delayed. The AUC $(0-t)$ of PF increased significantly $(P<0.01)$, the peak-reaching concentration and AUC $(0-\infty)$ increased, and the half-life and average retention time were shortened, indicating that TP absorption in rats may be delayed. After percutaneous administration of TP and PF, the content of TP in the heart, liver, spleen, lungs, and kidneys of male rats significantly decreased at $2 \mathrm{~h}(P<0.05)$ and the drug concentration in the liver tissues significantly decreased at $2 \mathrm{~h}, 4 \mathrm{~h}$, and $8 \mathrm{~h}(P<0.05)$. The TP content in the spleen of female rats significantly decreased at $2 \mathrm{~h}$ and $4 \mathrm{~h}$ $(P<0.05)$ and also decreased in other tissues, but not significantly. After percutaneous administration of TP and PF, the PF content in the heart, liver, spleen, lungs, and kidneys of male and female rats had no significant difference. However, after percutaneous administration of TP and PF, the TP concentration in the skin increased, suggesting that the amount of TP retained in the skin increased, thereby reducing its content in blood and tissues, producing a reduction in toxicity effect.
\end{abstract}

\section{Introduction}

Triptolide (TP) is an epoxy-xylene lactone compound. The common ingredient of Tripterygium wilfordii hook, TP, is responsible for anti-inflammatory, antitumor, antifertility, and immunomodulatory effects [1-3]. Clinically, TP has a clear curative effect on rheumatoid arthritis (RA), but its narrow therapeutic window and strong liver and kidney toxicity limit its safe clinical application [4]. Our research group used data mining technology to summarize and analyze the use of Tripterygium wilfordii in the treatment of rheumatoid arthritis [5-7]. It was found that Tripterygium wilfordii was often administered in combination with Paeonia lactiflora, and it was reported that the combination of the two could enhance efficacy and reduce toxicity [8-12]; however, these combinations were mostly orally administered. The mechanism of transdermal administration of Tripterygium wilfordii combined with Paeonia lactiflora is unclear. 
The transdermal drug delivery system (TDDS) refers to a system in which drugs are administered on the surface of the skin, pass through each layer of the skin at a constant rate, enter systemic circulation, and produce systemic or local therapeutic effects [13]. The preparation of TP as a topical preparation for transdermal administration is beneficial to reduce the first-pass effects and gastrointestinal tract toxicity and enable the drug to enter the systemic circulation in a small, continuous amount so as to reduce toxicity. It was found that transdermal administration of Tripterygium wilfordii can maintain a stable blood drug concentration [14]. Additionally, Tripterygium wilfordii has been prepared into microemulsion gel, and pharmacodynamic experiments conducted on CIA model rats found that the topical preparation of Tripterygium wilfordii had a curative effect $[15,16]$. However, long-term use alone still produces more serious toxicity to the organism.

Therefore, in this study, modern techniques and analytical methods were used to further study the pharmacokinetics and tissue distribution of TP and PF (the main active component of Paeonia lactiflora) after transdermal administration in order to explain the mechanism of toxicity reduction caused by combining the two drugs.

\section{Materials and Methods}

2.1. Materials. Triptolide (Chengdu Puffer Biotechnology Co., Ltd., Chengdu, China, purity $\geq 98 \%$ ), paeoniflorin (Chengdu Puffer Biotechnology Co., Ltd., purity $\geq 98 \%$ ), AB Triple Quadrupole 4500 (AB SCIEX, USA), AB Triple Quadrupole 5500 (AB SCIEX, USA), and Agilent InfinityLab Poroshell 120 SB-C18 $(2.1 \times 50 \mathrm{~mm}, 2.7 \mu \mathrm{m})$ were used.

2.2. Animals. Sprague Dawley (SD) rats weighing 220-250 g were obtained from Hunan Slake Jingda Experimental Animal Co., Ltd., and acclimated in the laboratory for seven days. Prior to the experiments, rats were housed with free access to food and water on a $12 \mathrm{~h}$ light-dark cycle at ambient temperature $\left(22-24^{\circ} \mathrm{C}\right)$ and roughly $50 \%$ relative humidity. All animal procedures were approved by the Ethics Committee of the Experimental Animal Science and Technology Center of Jiangxi University of Traditional Chinese Medicine (No. JZLLSC2019-0149).

2.3. Preparation of TP Cream. Oil phase contained isopropyl myristate (10\%), glyceryl monostearate (14\%), and Span-60 (2\%); aqueous phase contained Tween-80 (2\%), Garandam $(0.2 \%)$, and water $(68.8 \%)$; drug: $0.01 \%$ TP is dissolved in $3 \%$ anhydrous ethanol. First, the oil phase was preheated in a water bath at $80^{\circ} \mathrm{C}$ for $30 \mathrm{~min}$. Next, the drug was poured into the oil phase and stirred evenly, after which the water phase was quickly poured into the oil phase. The mixture was sheared at high speed of $10,000 \mathrm{r} \cdot \mathrm{min}^{-1}$ for $2 \mathrm{~min}$, stirred, and cooled in an ice-water bath to obtain TP cream.

2.4. Preparation of PF Cream. Oil phase contained isopropyl myristate (10\%), glyceryl monostearate (14\%), and Span-60 (2\%); aqueous phase contained Tween-80 (2\%), Garandam
$(0.2 \%)$, water $(58.2 \%)$, and PF $(10 \%)$. The oil phase was preheated in a water bath at $80^{\circ} \mathrm{C}$ for $30 \mathrm{~min}$, after which the water phase was quickly poured into the oil phase. The mixture was sheared at high speed of $10,000 \mathrm{r} \cdot \mathrm{min}^{-1}$ for 2 min, stirred, and cooled in an ice-water bath to obtain PF Cream.

2.5. Preparation of the Combination of TP and PF Cream (TP$P F)$. Oil phase contained isopropyl myristate (10\%), glyceryl monostearate (14\%), and Span-60 (2\%); aqueous phase contained Tween-80 (2\%), paeoniflorin (10\%), and Galandan (0.2\%), water (58.2\%); drug: $0.01 \% \mathrm{TP}$ is dissolved in $3 \%$ anhydrous ethanol. First, the oil phase was preheated in a water bath at $80^{\circ} \mathrm{C}$ for $30 \mathrm{~min}$. Next, the drug was poured into the oil phase and stirred evenly, after which the water phase was quickly poured into the oil phase. The mixture was sheared at high speed of $10,000 \mathrm{r} \cdot \mathrm{min}^{-1}$ for $2 \mathrm{~min}$, stirred, and cooled in an ice-water bath to obtain TP-PF cream.

2.6. Drug Administration and Sampling. For the pharmacokinetic study, rats were divided into three groups (six males and six females per group): the TP, PF, and TP-PF groups. Before the experiment, the rats were fasted for $16 \mathrm{~h}$ but allowed water. The back hair $(5 \mathrm{~cm} \times 4 \mathrm{~cm})$ of the rats was removed. TP $\left(1 \mathrm{mg} \cdot \mathrm{kg}^{-1} \cdot \mathrm{D}^{-1}\right)$, PF $\left(1 \mathrm{~g} \cdot \mathrm{kg}^{-1} \cdot \mathrm{D}^{-1}\right)$, and TP-PF creams were uniformly applied in the area from which the back hair was removed. The surface of the treatment area was covered with polyethylene and fixed with a medical adhesive cloth. Then, $0.25 \mathrm{~mL}$ blood samples were collected in heparinized Eppendorf tube via the posterior orbital venous plexus before dosing and subsequently at $0.083 \mathrm{~h}, 0.25 \mathrm{~h}, 0.5 \mathrm{~h}, 1 \mathrm{~h}, 2 \mathrm{~h}, 3 \mathrm{~h}, 4 \mathrm{~h}, 6 \mathrm{~h}, 8 \mathrm{~h}, 12 \mathrm{~h}$, and $24 \mathrm{~h}$. After centrifuging at $4000 \mathrm{r} \cdot \mathrm{min}^{-1}$ for $10 \mathrm{~min}$, the plasma samples were obtained and frozen at $-20^{\circ} \mathrm{C}$ until analysis. For the tissue distribution study, three groups of rats (six males and six females per group) underwent drug administration in the same manner. Heart, liver, spleen, lungs, kidneys, skin, ovaries, and testes were removed at $2 \mathrm{~h}, 4 \mathrm{~h}$, and $8 \mathrm{~h}$ after dosing. Tissue samples were weighed and rinsed with physiological saline solution; then, the samples were blotted using filter paper and stored at $-20^{\circ} \mathrm{C}$ until analysis.

2.7. Plasma and Tissues Samples Processing. In the analysis of biological samples in vivo, due to the low drug concentration, it is easy to produce large errors. Therefore, we added internal standards to reduce the errors in the sample processing process. In this article, we chose carbamazepine as the internal standard because the retention times of carbamazepine and triptolide and paeoniflorin were similar and the peak shape was better under the chromatographic conditions of the two, and they have passed the methodological verification.

To a $100 \mu \mathrm{L}$ aliquot of plasma sample, $10 \mu \mathrm{L}$ mixed standard, $10 \mu \mathrm{L}$ internal standard (IS) $(5 \mathrm{ng} / \mathrm{mL})$ working solution, and $20 \mu \mathrm{L}$ ammonia water were added in turn. All tissues were homogenized in triple normal saline. To a $100 \mu \mathrm{L}$ of tissues homogenate sample, $10 \mu \mathrm{L}$ mixed standard, 
$10 \mu \mathrm{L}$ IS $(5 \mathrm{ng} / \mathrm{mL})$ working solution, and $20 \mu \mathrm{L}$ ammonia water were added in turn. Plasma and tissue samples were then vortex-mixed for $30 \mathrm{~s}$ and extracted with $0.8 \mathrm{~mL}$ ethyl acetate by vortex mixing for $3 \mathrm{~min}$. After centrifugation at $12,000 \mathrm{r} \cdot \mathrm{min}^{-1}$ for $3 \mathrm{~min}, 0.78 \mathrm{~mL}$ upper organic layer was transferred. Next, $10 \mu \mathrm{L}$ ammonia and $400 \mu \mathrm{L}$ ethyl acetate were added to the lower layer and vortex-mixed for $2 \mathrm{~min}$. After centrifugation at $12,000 \mathrm{r} \cdot \mathrm{min}^{-1}$ for $3 \mathrm{~min}, 400 \mu \mathrm{L}$ upper organic layer was transferred, and the two upper organic layers were combined. The combined upper organic layer was evaporated to dryness at $50^{\circ} \mathrm{C}$ under a gentle stream of nitrogen. The residue was reconstituted in $100 \mu \mathrm{L}$ methanol, vortex-mixed for $1 \mathrm{~min}$, and centrifuged at $16,000 \mathrm{r} \cdot \mathrm{min}^{-1}$ for $10 \mathrm{~min}$. Finally, a $50 \mu \mathrm{L}$ aliquot was injected into the liquid chromatography-tandem mass spectrometry (LC-MS/MS) system for analysis.

2.8. LC-MS/MS Conditions and Method Validation. The chromatographic conditions for TP were as follows: solvent A was $0.1 \%$ formic acid $(\mathrm{V} / \mathrm{V})$ in water, and solvent $\mathrm{B}$ was a gradient elution with acetonitrile. The elution conditions were as follows: $0-1 \mathrm{~min}, 65 \% \mathrm{~A} ; 1-1.5 \mathrm{~min}, 65-52 \% \mathrm{~A}$; $1.5-2.5 \mathrm{~min}, 52 \%$ A; $2.5-2.6 \mathrm{~min}, 52 \%-10 \%$ A; $2.6-3.5 \mathrm{~min}$, $10 \% \mathrm{~A} ; 3.5-4.1 \mathrm{~min}, 10 \%-65 \% \mathrm{~A} ; 4.1-5 \mathrm{~min}, 65 \% \mathrm{~A}$. The flow rate was $0.4 \mathrm{~mL} / \mathrm{min}$, and the column temperature was $40^{\circ} \mathrm{C}$. The TP was detected in positive ion mode. An electrospray ion source was used, and the ion source temperature was $550^{\circ} \mathrm{C}$, ionized voltage was $5500 \mathrm{~V}$, curtain gas was at $35 \mathrm{psi}$, and impact gas was at 7 psi. Auxiliary gas 1 (GS1) was 55 psi, auxiliary gas 2 (GS2) was 50 psi, inlet voltage (EP) was $10 \mathrm{~V}$, and outlet voltage (CXP) was $14 \mathrm{~V}$. The quantification ion pairs of TP were $361.2 / 144.8$. Additionally, the quantification ion pairs of internal carbamazepine were 236.8/194.0.

The chromatographic conditions for PF were as follows: solvent $A$ was $0.1 \%$ formic acid $(\mathrm{V} / \mathrm{V})$ in water, and solvent $\mathrm{B}$ was a gradient elution with acetonitrile. The elution conditions were as follows: $0-1 \mathrm{~min}, 90-65 \% \mathrm{~A} ; 1-1.5 \mathrm{~min}$, 65-44\% A; $1.5-3 \mathrm{~min}, 44 \%$ A; $3-3.1 \mathrm{~min}, 44 \%-90 \%$ A; $3.1-5 \mathrm{~min}, 90 \% \mathrm{~A}$. The flow rate was $0.35 \mathrm{~mL} / \mathrm{min}$, and the column temperature was $40^{\circ} \mathrm{C}$. The TP was detected in positive ion mode. An electrospray ion source was used, and the ion source temperature was $550^{\circ} \mathrm{C}$, ionized voltage was $5500 \mathrm{~V}$, curtain gas was at $35 \mathrm{psi}$, and impact gas was at 9 psi. Auxiliary gas 1 (GS1) was 50 psi; auxiliary gas 2 (GS2) was 50 psi; inlet voltage (EP) was $10 \mathrm{~V}$; outlet voltage (CXP) was $6 \mathrm{~V}$. The quantification ion pairs of PF were 498.2/179.0. Also, the quantification ion pairs of internal carbamazepine were 236.8/194.0.

2.9. Statistical Analysis. All the data were expressed as mean \pm standard deviation (SD), and statistical analyses were performed by SPSS 17.0. The pharmacokinetic data were fitted by DAS 2.0 software and then tested by SPSS 17.0. Pharmacokinetic parameters and analyte levels in the male and female rats were assessed by one-way ANOVA followed by a least-significant-difference test. $P<0.05$ was considered to indicate statistical significance, and $P<0.01$ was deemed to indicate a highly significant difference.

\section{Results}

3.1. Specificity. Specificity was evaluated by comparing the chromatogram of blank plasma with that of blank plasma spiked with the mixed standard of TP $(400 \mathrm{ng} / \mathrm{mL})$ and PF $(90,000 \mathrm{ng} / \mathrm{mL})$, as previously described and that of plasma obtained from rats after administration of TP and PF after treatment for $30 \mathrm{~min}$, respectively. For the pharmacokinetic study, the results showed that TP, PF, and IS were eluted, and no detectable interfering peaks were found (Figure S1). For the tissue distribution study, the result showed that TP, $\mathrm{PF}$, and IS were eluted, and no detectable interfering peaks were found (Figure S2).

3.2. Linearity. Linearity of the developed analytical method was investigated by analyzing the matrix-matched construction via an internal standard approach, using mixed probe drugs at a series of concentrations. TP was used at the following concentrations: 50, 100, 250, 500, 1250, 2500, and $5000 \mathrm{ng} / \mathrm{mL}$ at $25^{\circ} \mathrm{C}$. PF was used at concentrations of 1,5 , $10,100,250,500$, and $1000 \mu \mathrm{g} / \mathrm{mL}$. IS was used at concentrations of $5 \mathrm{ng} / \mathrm{mL}$. Taking the ratio of the target component to the peak area of IS as the longitudinal coordinate and the concentration as the transverse coordinate, linear regression was performed. The standard curve was drawn with the reciprocal of the concentration as the weighted coefficient. For the pharmacokinetic study, the calibration curves constructed by plotting the peak area ratios of TP and PF to IS versus the nominal concentrations in the standard biological samples using linear regression analysis are listed in Table 1. The calibrations were linear over a certain range in all matrices, and the correlation coefficients $\left(r^{2}\right)$ of TP and PF were 0.9949 and 0.9928 , respectively. For the tissue distribution study, the linear regression analysis is listed in Tables 2 and 3. The correlation coefficients $\left(r^{2}\right)$ of TP in the heart, liver, spleen, lungs, kidneys, skin, ovaries, and testes were $0.9979,0.9941,0.9991$, $0.999,0.9981,0.9985,0.9949$, and 0.998 , respectively. The correlation coefficients $\left(r^{2}\right)$ of PF in the heart, liver, spleen, lungs, kidneys, skin, ovaries, and testes were 0.998, 0.996, $0.997,0.997,0.993,0.995,0.998$, and 0.993 , respectively.

3.3. Accuracy and Precision. In total, six replicate analyses of the quality control (QC) samples (TP, PF, and IS) were prepared at three different concentrations (the concentrations of TP were $150 \mathrm{ng} / \mathrm{mL}, 500 \mathrm{ng} / \mathrm{mL}$, and $4000 \mathrm{ng} / \mathrm{mL}$, and the concentrations of PF and IS were $3 \mu \mathrm{g} / \mathrm{mL}, 100 \mu \mathrm{g} /$ $\mathrm{mL}$, and $900 \mu \mathrm{g} / \mathrm{mL}$ ) on the same day to ensure interday accuracy and precision. The present study estimated the intraday precision by analyzing six replicate QC samples on three consecutive days. The relative standard deviation (RSD) was used to assess precision, and accuracy was defined as the percent ratios of the calculated concentration to the nominal concentrations. For the pharmacokinetic study, the intra- and interday precision and accuracy for QC samples are listed in Table 4. For the tissue distribution study, the intra- and interday precision and accuracy for QC samples 
TABLE 1: Calibration curves for TP and PF in plasma.

\begin{tabular}{lccc}
\hline Plasma samples & Linear ranges $\left(\mathrm{ng} \cdot \mathrm{mL}^{-1}\right)$ & Calibration curves & Correlation coefficients \\
\hline Triptolide & $5-500$ & $Y=0.0036 X-0.0163$ & $r^{2}=0.9949$ \\
Paeoniflorin & $100-100000$ & $Y=0.0003 X-0.11$ & $r^{2}=0.9928$ \\
\hline
\end{tabular}

TABLE 2: Regression equation and linearity range of TP in tissues.

\begin{tabular}{lccc}
\hline Tissues & Linearity range $\left(\mathrm{ng} \cdot \mathrm{mL}^{-1}\right)$ & Calibration curves & Correlation coefficients \\
\hline Heart & $5-500$ & $Y=0.011 X+0.0175$ & $r^{2}=0.9979$ \\
Liver & $5-500$ & $Y=0.0125 X-0.1381$ & $r^{2}=0.9941$ \\
Spleen & $5-500$ & $Y=0.0117 X-0.0565$ & $r^{2}=0.9991$ \\
Lung & $5-500$ & $Y=0.0125 X-0.0856$ & $r^{2}=0.999$ \\
Kidney & $5-500$ & $Y=0.0125 X-0.0631$ & $r^{2}=0.9981$ \\
Skin & $5-500$ & $Y=0.0142 X-0.1261$ & $r^{2}=0.9985$ \\
Ovaries & $5-500$ & $Y=0.0149 X-0.1673$ & $r^{2}=0.9949$ \\
Testis & $5-500$ & $Y=0.0119 X-0.1118$ & $r^{2}=0.998$ \\
\hline
\end{tabular}

TABle 3: Regression equation and linearity range of PF in tissues.

\begin{tabular}{lccc}
\hline Tissues & Linearity range $\left(\mathrm{ng} \cdot \mathrm{mL}^{-1}\right)$ & Calibration curves & Correlation coefficients \\
\hline Heart & $100-100000$ & $Y=0.00004 X+0.5649$ & $r^{2}=0.998$ \\
Liver & $100-100000$ & $Y=0.00005 X+0.5589$ & $r^{2}=0.996$ \\
Spleen & $100-100000$ & $Y=0.0001 X+0.649$ & $r^{2}=0.997$ \\
Lung & $100-100000$ & $Y=0.0001 X+0.466$ & $r^{2}=0.997$ \\
Kidney & $100-100000$ & $Y=0.00008 X+0.5319$ & $r^{2}=0.993$ \\
Skin & $100-100000$ & $Y=0.00006 X+0.5658$ & $r^{2}=0.995$ \\
Ovaries & $100-100000$ & $Y=0.00006 X+0.6135$ & $r^{2}=0.998$ \\
Testis & $100-100000$ & $Y=0.00006 X+0.6526$ & $r^{2}=0.993$ \\
\hline
\end{tabular}

are listed in Tables 5 and 6 . It was demonstrated that the results were all acceptable (RSD, <15\%).

3.4. Recovery Rate. The ratio of the actual measured concentration to the marked concentration was used to determine the recovery rate of the analytical method. For the pharmacokinetic study, the recovery rate of TP was acceptable, the RSD of TP and PF was less than 15\%, and there was no obvious matrix effect (Table S1). For the tissue distribution study, the recovery rate of TP was higher in the homogenate of different tissues. The RSD of TP and PF was less than $15 \%$, and there was no obvious matrix effect (Tables S2 and S3).

3.5. Stability. QC samples at three concentrations (low, medium, and high) were used to assess the freeze-thaw cycle stabilities of the mixed TP, PF, and IS. All QC samples were stored at $-80^{\circ} \mathrm{C}$ and subjected to three freeze-thaw cycles. Each cycle lasted for $20 \mathrm{~h}$, and the concentrations were determined using LC-MS. For the pharmacokinetic study, the results of stability studies showed that the RSD was less than $15 \%$, indicating that the sample has good stability under various conditions (Tables S4 and S5). For the tissue distribution study, the results of stability studies showed that the stability of the sample was good under various conditions (Tables S6 and S7).
3.6. Pharmacokinetics. The plasma concentration-time curves of TP and PF in each group of creams after transdermal administration are depicted in Figure 1. The corresponding pharmacokinetic parameters generated by fitting plasma concentration profiles to a noncompartmental model are listed in Table 7 . The results showed that both TP and PF can be rapidly absorbed in the body and slowly eliminated after reaching a certain level, and both compartment models were two-compartment models. After transdermal administration of the combination of TP and $\mathrm{PF}$, the $\mathrm{AUC}_{(0-\infty)}$ of TP in the combination group increased $(P<0.01), C_{\max }$ was decreased by $58.17 \%$, the AUC $(0-t)$ showed no significant change, and the half-life and average residence time were also extended $(P>0.05)$. The AUC $(0-t)$ of $\mathrm{PF}$ in the compatibility group was increased $(P<0.01)$. Both $\mathrm{C}_{\text {max }}$ and AUC $(0-\infty)$ were increased, and the half-life and average residence time were shortened $(P>0.05)$.

\subsection{Changes of TP in Tissues before and after Compatibility.} During the methodological investigation, we did a study on the distribution of blank tissue, and the results showed that the blank had no effect on triptolide and paeoniflorin. After transdermal administration of the combination of TP and $\mathrm{PF}$, the content of TP in the heart, liver, spleen, lungs, and kidneys of male rats was decreased at $2 \mathrm{~h}(P<0.05)$, and the drug concentration in liver tissue was decreased at $2 \mathrm{~h}, 4 \mathrm{~h}$, and $8 \mathrm{~h}(P<0.05)$ (Figure $2(\mathrm{a}))$. The content of TP in the 
TABLE 4: Accuracy and precision of TP and PF in plasma $(n=6)$.

\begin{tabular}{|c|c|c|c|c|c|c|c|}
\hline \multirow[b]{2}{*}{ Analyses } & \multirow[b]{2}{*}{$\begin{array}{l}\text { Spiked concentration } \\
\quad\left(\mathrm{ng} \cdot \mathrm{mL}^{-1}\right)\end{array}$} & \multicolumn{3}{|c|}{ Intraday } & \multicolumn{3}{|c|}{ Interday } \\
\hline & & $\begin{array}{c}\text { Found } \\
\text { concentration } \\
(\text { mean } \pm S D)\end{array}$ & $\begin{array}{l}\text { Precision } \\
(\mathrm{RSD}, \%)\end{array}$ & $\begin{array}{l}\text { Accuracy } \\
(\mathrm{RE}, \%)\end{array}$ & $\begin{array}{c}\text { Found } \\
\text { concentration } \\
(\text { mean } \pm \text { SD })\end{array}$ & $\begin{array}{l}\text { Precision } \\
(\mathrm{RSD}, \%)\end{array}$ & $\begin{array}{l}\text { Accuracy } \\
\text { (RE, \%) }\end{array}$ \\
\hline \multirow{3}{*}{ Triptolide } & 15 & $13.25 \pm 0.74$ & 5.62 & -11.66 & $14.01 \pm 0.74$ & 5.31 & -6.59 \\
\hline & 50 & $55.91 \pm 6.64$ & 11.87 & 11.82 & $56.36 \pm 2.21$ & $3.92 \%$ & 12.71 \\
\hline & 400 & $376.67 \pm 37.69$ & 10.01 & -5.83 & $386.97 \pm 37.69$ & 9.74 & -3.26 \\
\hline \multirow{3}{*}{ Paeoniflorin } & 300 & $302.48 \pm 19.80$ & 6.55 & 0.83 & $303.40 \pm 22.21$ & 7.32 & 1.13 \\
\hline & 10000 & $10513.17 \pm 1088.58$ & 10.35 & 5.13 & $10488.17 \pm 1066.05$ & 10.16 & 4.88 \\
\hline & 90000 & $89246.50 \pm 9568.47$ & 10.72 & -0.84 & $87496.50 \pm 10240.51$ & 11.70 & -2.78 \\
\hline
\end{tabular}

TABle 5: Accuracy and precision of TP in tissues $(n=5)$.

\begin{tabular}{|c|c|c|c|c|c|c|c|}
\hline \multirow[b]{2}{*}{ Tissue } & \multirow{2}{*}{$\begin{array}{c}\text { Spiked } \\
\left(\mathrm{ng} \cdot \mathrm{mL}^{-1}\right)\end{array}$} & \multicolumn{3}{|c|}{ Intraday } & \multicolumn{3}{|c|}{ Interday } \\
\hline & & $\begin{array}{c}\text { Concentration } \\
(\text { mean } \pm S D)\end{array}$ & $\begin{array}{l}\text { Precision } \\
(\mathrm{RSD}, \%)\end{array}$ & $\begin{array}{l}\text { Accuracy } \\
\text { (RE, \%) }\end{array}$ & $\begin{array}{c}\text { Concentration } \\
(\text { mean } \pm S D)\end{array}$ & $\begin{array}{l}\text { Precision } \\
\text { (RSD, \%) }\end{array}$ & $\begin{array}{c}\text { Accuracy } \\
\text { (RE, \%) }\end{array}$ \\
\hline \multirow{3}{*}{ Heart } & 15 & $14.61 \pm 1.21$ & 8.31 & -2.61 & $14.99 \pm 1.35$ & 8.98 & -0.07 \\
\hline & 40 & $38.50 \pm 1.50$ & 3.90 & -3.74 & $38.92 \pm 1.70$ & 4.36 & -2.71 \\
\hline & 400 & $394.28 \pm 11.34$ & 2.88 & -1.43 & $398.76 \pm 30.32$ & 7.60 & -0.31 \\
\hline \multirow{3}{*}{ Liver } & 15 & $16.37 \pm 0.08$ & 0.48 & 9.14 & $16.18 \pm 0.28$ & 1.75 & 7.88 \\
\hline & 40 & $41.00 \pm 0.71$ & 1.72 & 2.51 & $40.91 \pm 0.59$ & 1.43 & 2.28 \\
\hline & 400 & $404.81 \pm 9.48$ & 2.34 & 1.20 & $385.93 \pm 20.37$ & 5.28 & -3.52 \\
\hline \multirow{3}{*}{ Spleen } & 15 & $15.06 \pm 0.36$ & 2.40 & 0.41 & $15.04 \pm 0.34$ & 2.24 & 0.29 \\
\hline & 40 & $36.01 \pm 1.59$ & 4.41 & -9.97 & $35.51 \pm 1.60$ & 4.51 & -11.22 \\
\hline & 400 & $435.69 \pm 2.71$ & 0.62 & 8.92 & $424.61 \pm 11.28$ & 2.66 & 6.15 \\
\hline \multirow{3}{*}{ Lung } & 15 & $14.46 \pm 0.12$ & 0.82 & -3.60 & $14.52 \pm 0.11$ & 0.77 & -3.18 \\
\hline & 40 & $42.65 \pm 0.40$ & 0.93 & 6.62 & $42.82 \pm 0.49$ & 1.13 & 7.06 \\
\hline & 400 & $381.37 \pm 6.12$ & 1.60 & -4.66 & $386.76 \pm 7.15$ & 1.85 & -3.31 \\
\hline \multirow{3}{*}{ Kidney } & 15 & $14.15 \pm 0.63$ & 4.46 & -5.67 & $14.33 \pm 0.68$ & 4.74 & -4.48 \\
\hline & 40 & $44.76 \pm 2.61$ & 5.83 & 11.90 & $44.57 \pm 2.28$ & 5.12 & 11.42 \\
\hline & 400 & $422.50 \pm 17.61$ & 4.17 & 5.63 & $414.30 \pm 18.52$ & 4.47 & 3.57 \\
\hline \multirow{3}{*}{ Skin } & 15 & $16.67 \pm 0.23$ & 1.39 & 11.14 & $16.73 \pm 0.22$ & 1.31 & 11.56 \\
\hline & 40 & $43.19 \pm 1.12$ & 2.59 & 7.98 & $43.63 \pm 1.81$ & 4.15 & 9.09 \\
\hline & 400 & $436.20 \pm 10.90$ & 2.50 & 9.05 & $441.32 \pm 16.55$ & 3.75 & 10.33 \\
\hline \multirow{3}{*}{ Ovaries } & 15 & $15.97 \pm 0.48$ & 2.98 & 6.48 & $15.99 \pm 0.68$ & 4.27 & 6.58 \\
\hline & 40 & $44.05 \pm 2.86$ & 6.49 & 10.12 & $45.08 \pm 3.34$ & 7.40 & 12.69 \\
\hline & 400 & $440.01 \pm 30.11$ & 6.84 & 10.00 & $442.19 \pm 28.03$ & 6.34 & 10.55 \\
\hline \multirow{3}{*}{ Testis } & 15 & $16.25 \pm 0.42$ & 2.60 & 8.32 & $16.34 \pm 0.22$ & 1.35 & 8.91 \\
\hline & 40 & $44.07 \pm 1.05$ & 2.38 & 10.17 & $44.39 \pm 1.20$ & 2.71 & 10.98 \\
\hline & 400 & $387.58 \pm 10.05$ & 2.98 & -3.11 & $385.66 \pm 4.35$ & $1.13 \%$ & -3.59 \\
\hline
\end{tabular}

spleen of female rats was decreased at $2 \mathrm{~h}$ and $4 \mathrm{~h}(P<0.05)$ and was decreased in other tissues as well $(P>0.05)$ (Figure 2(b)). There was no significant difference in the content of PF in the heart, liver, spleen, lungs, and kidneys of male and female rats after transdermal administration of the combination of TP and PF $(P>0.05)$ (Figures 2(c) and 2(d)). After transdermal administration of the combination of TP and $\mathrm{PF}$, the concentration of $\mathrm{TP}$ in the skin increased $(P<0.05)$ (Figure 3).

\section{Discussion}

After the transdermal administration of the combination of TP and PF, there was no significant difference in the area under the blood concentration-time curve of TP, the peak concentration decreased, and the peak time was delayed, indicating that the absorption of TP in rats was slowed and delayed after the combined administration of the two drugs. The change of the drug-time curve also showed that TP had a more stable blood concentration change after compatibility. The above suggested that the compatibility of the two may weaken the toxicity of TP after percutaneous administration. $C_{\max }$ of PF increased by 2.38 times; $\mathrm{AUC}_{(0-t)}$, peak concentration and $\mathrm{AUC}_{(0-\infty)}$ increased; and half-life and average retention time were shortened, suggesting that the combination of the two drugs can promote the transdermal absorption of PF after percutaneous administration and may enhance its efficacy [17]. This could be due to the fact that TP can cause swelling and ulceration of the skin of rats [9], reducing the barrier function of the skin, which may increase 
TABLE 6: Accuracy and precision of PF in tissues $(n=5)$.

\begin{tabular}{|c|c|c|c|c|c|c|c|}
\hline \multirow[b]{2}{*}{ Tissue } & \multirow{2}{*}{$\begin{array}{c}\text { Spiked } \\
\left(\mathrm{ng} \cdot \mathrm{mL}^{-1}\right)\end{array}$} & \multicolumn{3}{|c|}{ Intraday } & \multicolumn{3}{|c|}{ Interday } \\
\hline & & $\begin{array}{l}\text { Concentration } \\
(\text { mean } \pm \mathrm{SD})\end{array}$ & $\begin{array}{l}\text { Precision } \\
(\mathrm{RSD}, \%)\end{array}$ & $\begin{array}{c}\text { Accuracy } \\
(\mathrm{RE}, \%)\end{array}$ & $\begin{array}{c}\text { Concentration } \\
(\text { mean } \pm S D)\end{array}$ & Precision (RSD, \%) & Accuracy (RE, \%) \\
\hline \multirow{3}{*}{ Heart } & 300 & $343.42 \pm 12.14$ & 3.53 & 14.47 & $327.72 \pm 21.19$ & 6.47 & 9.24 \\
\hline & 10000 & $9644.25 \pm 304.18$ & 3.15 & -3.56 & $9541.73 \pm 361.92$ & 3.79 & -4.58 \\
\hline & 90000 & $96372.10 \pm 8760.18$ & 9.09 & 7.08 & $98474.31 \pm 13288.96$ & 13.49 & 9.42 \\
\hline \multirow{3}{*}{ Liver } & 300 & $335.11 \pm 38.61$ & 11.52 & 11.70 & $337.11 \pm 28.16$ & 8.35 & 12.37 \\
\hline & 10000 & $9586.85 \pm 283.46$ & 2.96 & -4.13 & $8970.58 \pm 980.56$ & 10.93 & -10.29 \\
\hline & 90000 & $87937.55 \pm 4493.29$ & 5.11 & -2.29 & $87986.22 \pm 3833.75$ & 4.36 & -2.24 \\
\hline \multirow{3}{*}{ Spleen } & 300 & $308.90 \pm 44.73$ & 14.48 & 2.97 & $314.58 \pm 41.18$ & 13.09 & 4.86 \\
\hline & 10000 & $9557.40 \pm 306.28$ & 3.20 & -4.43 & $9606.79 \pm 377.57$ & 3.93 & -3.93 \\
\hline & 90000 & $94573.89 \pm 11563.05$ & 12.23 & 5.08 & $91691.47 \pm 12416.90$ & 13.54 & 1.88 \\
\hline \multirow{3}{*}{ Lung } & 300 & $275.21 \pm 31.98$ & 9.77 & -8.26 & $273.96 \pm 23.21$ & 8.47 & -4.62 \\
\hline & 10000 & $8870.60 \pm 1009.65$ & 11.38 & -11.29 & $9099.30 \pm 957.97$ & 10.53 & -9.01 \\
\hline & 90000 & $86423.35 \pm 8446.97$ & 11.62 & -3.97 & $85838.68 \pm 8825.90$ & 10.28 & -8.68 \\
\hline \multirow{3}{*}{ Kidney } & 300 & $319.14 \pm 21.46$ & 6.72 & 6.38 & $314.52 \pm 30.42$ & 9.67 & 4.84 \\
\hline & 10000 & $8674.69 \pm 538.08$ & 6.20 & -13.25 & $8895.32 \pm 618.98$ & 6.96 & -11.05 \\
\hline & 90000 & $88127.48 \pm 4606.73$ & 5.23 & -2.08 & $84696.41 \pm 5361.51$ & 6.33 & -5.89 \\
\hline \multirow{3}{*}{ Skin } & 300 & $307.29 \pm 12.17$ & 3.96 & 2.43 & $317.74 \pm 17.37$ & 5.47 & 5.91 \\
\hline & 10000 & $8811.53 \pm 498.49$ & 5.66 & -11.88 & $9125.19 \pm 553.29$ & 6.06 & -8.75 \\
\hline & 90000 & $94989.87 \pm 3753.00$ & 3.95 & 5.54 & $94842.02 \pm 2849.43$ & 3.00 & 5.38 \\
\hline \multirow{3}{*}{ Ovaries } & 300 & $319.54 \pm 19.73$ & 6.17 & 6.51 & $309.61 \pm 33.47$ & 10.81 & 3.20 \\
\hline & 10000 & $9129.07 \pm 475.45$ & 5.21 & -8.71 & $8844.32 \pm 965.24$ & 10.91 & -11.56 \\
\hline & 90000 & $93800.86 \pm 5510.22$ & 5.87 & 4.22 & $94747.39 \pm 12999.54$ & 13.72 & 5.27 \\
\hline \multirow{3}{*}{ Testis } & 300 & $303.83 \pm 30.03$ & 9.89 & 1.28 & $308.22 \pm 24.09$ & 7.82 & 2.74 \\
\hline & 10000 & $9143.88 \pm 305.43$ & 3.34 & -8.56 & $9379.53 \pm 530.38$ & 5.65 & -6.20 \\
\hline & 90000 & $95800.87 \pm 7372.54$ & 7.70 & 6.45 & $93591.79 \pm 8891.62$ & 9.50 & 3.99 \\
\hline
\end{tabular}

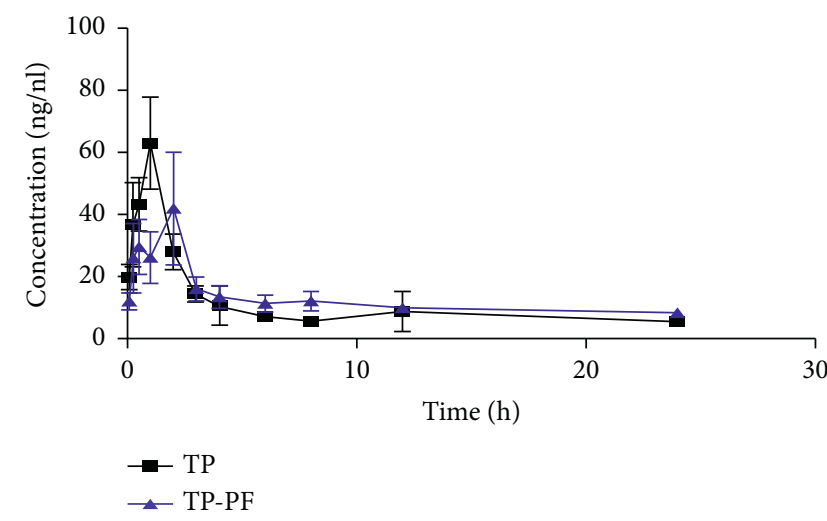

(a)

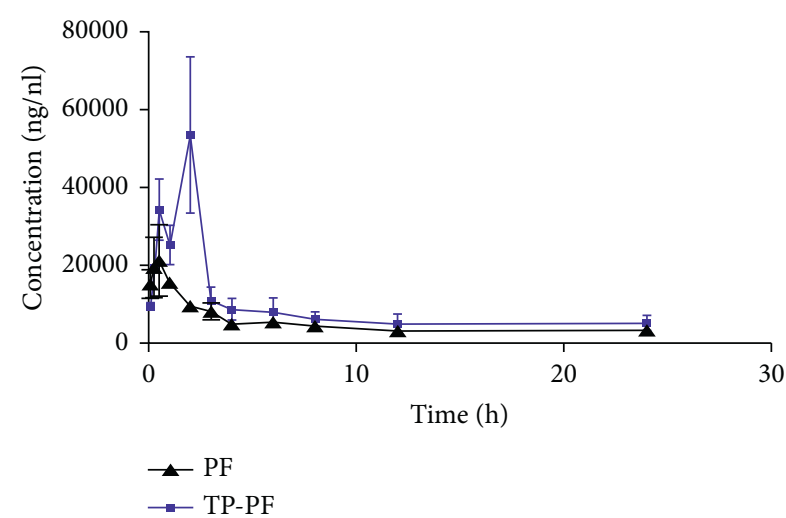

(b)

FIgURE 1: Blood concentration-time curve before and after compatibility. (a) TP. (b) PF.

the absorption of PF. PF reduces the levels of skin inflammatory factors and relieves the symptoms of skin lesions [18], which may slow the absorption of TP.

After transdermal administration of TP and PF, the content of TP in the tissues of male rats decreased. This may be caused by the specific expression of CYP3A2 in male rats and the accelerated metabolism of TP [19]. However, after the two drugs were percutaneously administered, the concentration of TP in the skin increased, suggesting that the amount of TP retained in the skin increased, thereby reducing its content in the blood and tissues, which in turn may have caused an attenuation effect. It was found that the skin of male rats was thicker than that of female rats [20]. These study results showed that the content of TP in male rats skin was higher than that in female rats skin after compatibility at $2 \mathrm{~h}$ and $4 \mathrm{~h}$, which may be related to the difference of male and female skin barrier. The ovaries of female rats in the TP group had higher concentrations of TP, suggesting that TP may have strong female reproductive organ toxicity [21]. It was found that the skin of male rats was thicker than that of female rats. This study results showed that the content of TP in male rats skin was 
TABLE 7: Main pharmacokinetic parameters of TP and PF in rats.

\begin{tabular}{lcccc}
\hline \multirow{2}{*}{ Parameters } & \multicolumn{2}{c}{ Triptolide } & \multicolumn{2}{c}{ Paeoniflorin } \\
& TP & TP-PF & PF & TP-PF \\
\hline$C_{\max }(\mu \mathrm{g} / \mathrm{L})$ & $63.42 \pm 17.40$ & $36.89 \pm 12.73$ & $22383.66 \pm 7768.60$ & $53314.70 \pm 19958.50$ \\
$T_{\max }(\mathrm{h})$ & $0.88 \pm 0.23$ & $2.25 \pm 1.23$ & $0.75 \pm 0.29$ & $2.08 \pm 2.11$ \\
$t 1 / 2 z(\mathrm{~h})$ & $26.18 \pm 17.22$ & $59.15 \pm 63.89$ & $37.27 \pm 12.70$ & $16.37 \pm 8.05$ \\
AUC $(0-t)\left(\mu \mathrm{g} / \mathrm{L}^{*} \mathrm{~h}\right)$ & $247.95 \pm 54.35$ & $289.57 \pm 37.30$ & $113701.69 \pm 7470.15$ & $214379.35 \pm 24618.58^{* *}$ \\
AUC $(0-\infty)\left(\mu \mathrm{g} / \mathrm{L}^{*} \mathrm{~h}\right)$ & $569.22 \pm 264.16$ & $987.70 \pm 728.02^{* *}$ & $287530.42 \pm 98387.10$ & $337060.99 \pm 120757.76$ \\
MRT $(0-t)(\mathrm{h})$ & $7.56 \pm 1.22$ & $9.42 \pm 0.84$ & $8.58 \pm 0.71$ & $7.58 \pm 1.36$ \\
MRT $(0-\infty)(\mathrm{h})$ & $30.85 \pm 22.54$ & $82.67 \pm 90.21$ & $50.01 \pm 19.60$ & $22.86 \pm 12.40$ \\
CLz/F $(\mathrm{L} / \mathrm{h} / \mathrm{kg})$ & $2.01 \pm 0.74$ & $1.35 \pm 0.63$ & $3.78 \pm 1.22$ & $3.25 \pm 1.07$ \\
Vz/f $(\mathrm{L} / \mathrm{kg})$ & $82.04 \pm 51.74$ & $73.98 \pm 23.85$ & $68.22 \pm 18.27$ & $187.44 \pm 5.28$ \\
\hline
\end{tabular}

Compared with the monodrug group, ${ }^{*} P<0.05$ and ${ }^{* *} P<0.01$.

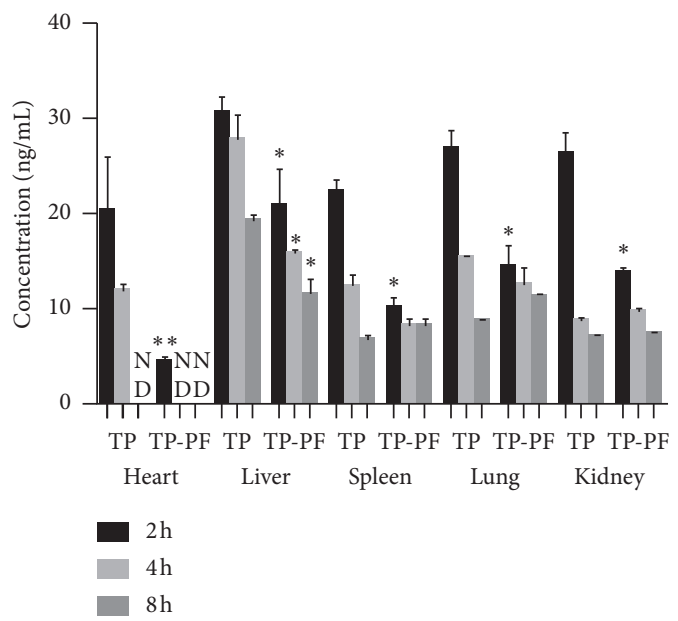

(a)

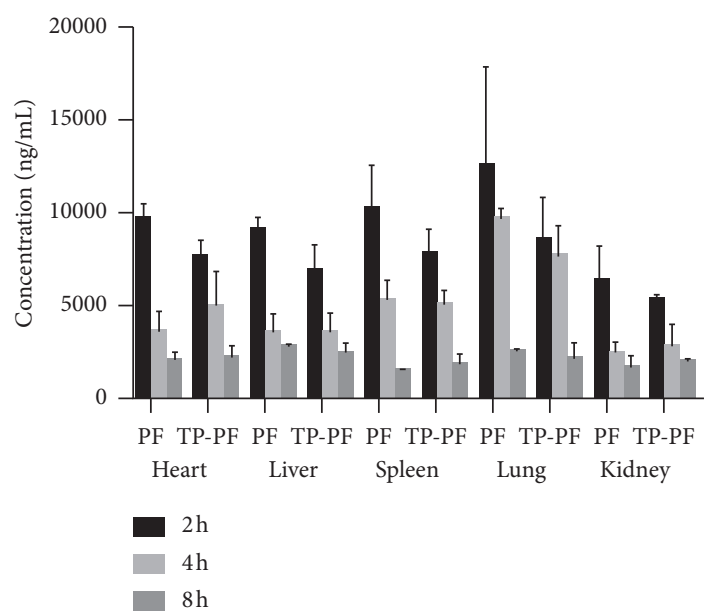

(c)

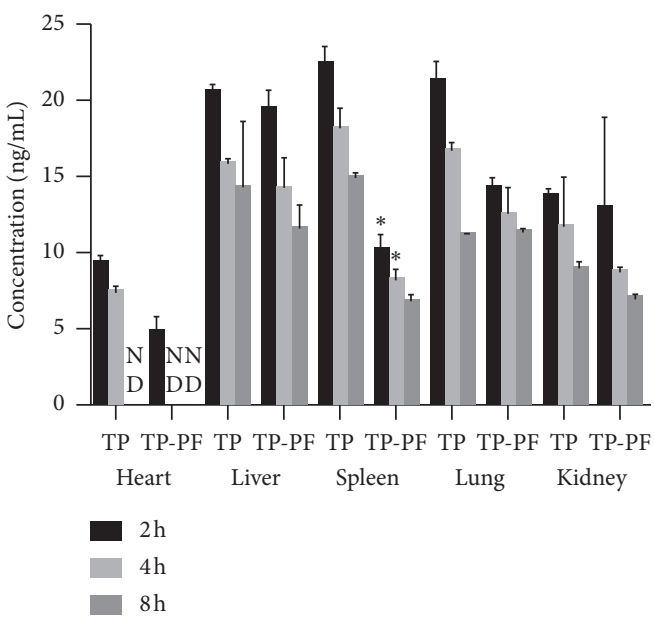

(b)

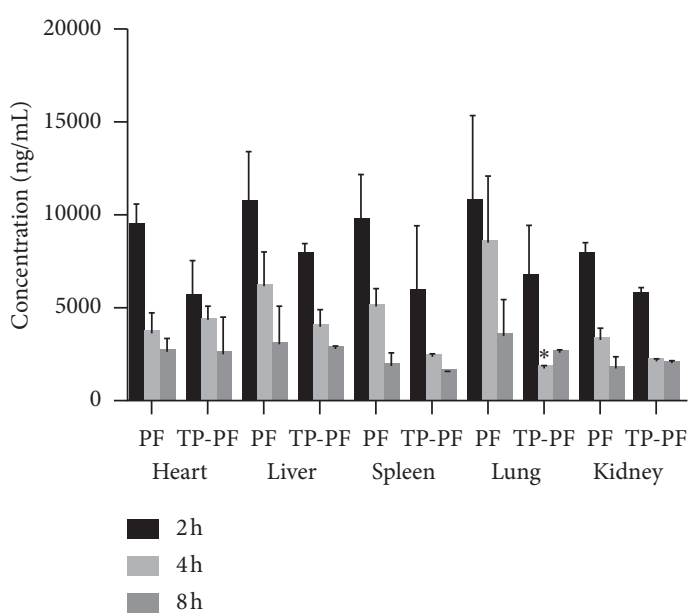

(d)

FIGURE 2: (a) Concentration changes of TP in heart, liver, spleen, lung, and kidney before and after TP combined with PF in male rats. (b) Concentration changes of TP in heart, liver, spleen, lung, and kidney before and after TP combined with PF in female rats. (c) Concentration changes of PF in heart, liver, spleen, lung, and kidney before and after TP combined with PF in male rats. (d) Concentration changes of PF in heart, liver, spleen, lung, and kidney before and after TP combined with PF in female rats. During the methodological investigation, we did a study on the distribution of blank tissue, and the results showed that the blank had no effect on triptolide and paeoniflorin. ${ }^{*} P<0.05$, a significant difference from TP group; ${ }^{* *} P<0.01$, highly significant from TP group; ND, no detected.

higher than that in female rats skin after compatibility, which may be related to the difference of male and female skin barrier.
In conclusion, this is the first report to evaluate the pharmacokinetics and tissue distribution of the combination of TP and PF in rats after transdermal administration. The 


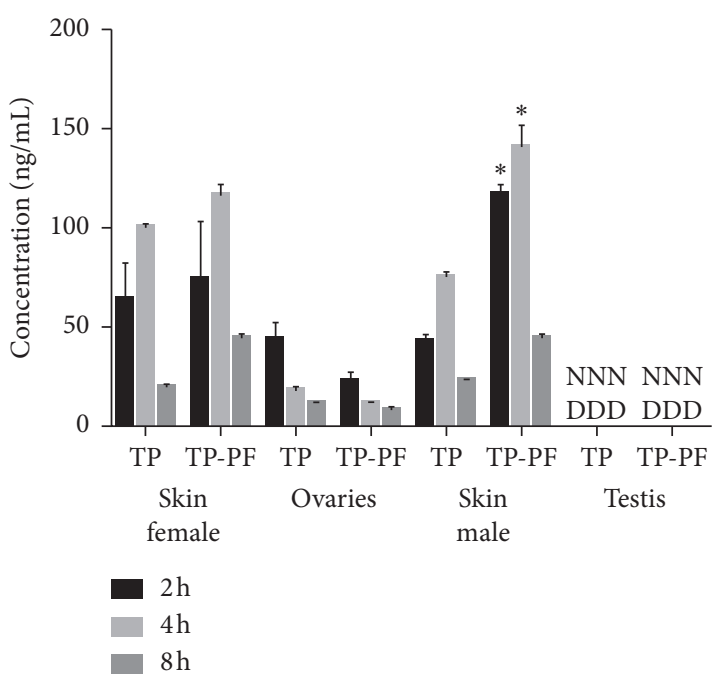

FIGURE 3: Concentration changes of TP in skin, ovaries, and testes before and after TP combined with PF in rats. ${ }^{*} P<0.05$, a significant difference from TP group; ${ }^{* *} P<0.01$, highly significant from TP group.

absorption of TP in rats was slowed and delayed. Additionally, the change of plasma concentration was more stable, and the absorption of PF in rats was accelerated. Furthermore, the TP content in the heart, spleen, lungs, and kidneys of male rats decreased significantly at $2 \mathrm{~h}$. The drug concentration in liver tissue decreased significantly at $2 \mathrm{~h}$, $4 \mathrm{~h}$, and $8 \mathrm{~h}$. However, there was no significant difference in the PF content in the heart, liver, spleen, lungs, and kidneys. In this report, we studied the pharmacological effects and tissue distribution of the combination of TP and PF after transdermal administration in male and female rats for the first time. This work will provide useful information for the clinical application and further research of TP.

\section{Data Availability}

All datasets presented in this study are included within the article/supplementary material.

\section{Ethical Approval}

The study was approved by the Ethics Committee of the Experimental Animal Science and Technology Center of Jiangxi University of Traditional Chinese Medicine (No. JZLLSC2019-0149).

\section{Conflicts of Interest}

All authors declare no conflicts of interest.

\section{Authors' Contributions}

YMG designed the experiments and checked the manuscript. QS and LFH performed pharmacokinetics and tissue distribution. WFZ and LHC participated in the discussion and prepared the chart. LLL performed statistical analyses. The corresponding authors LMC and ZZZ guided the formation of the entire manuscript. All authors contributed to the article and approved the submitted version.

\section{Acknowledgments}

This study was supported by the National Natural Science Foundation of China (82060722), Jiangxi Natural Science Foundation (20202BAB206081), and Jiangxi University of Traditional Chinese Medicine 1050 Youth Talent Project (5142001007).

\section{Supplementary Materials}

Figure S1: chromatograms of plasma. (A) Blank plasma sample of TP group; (B) blank spiked with TP (I) and carbamazepine (II); (C) samples after $30 \mathrm{~min}$ of administration TP (I) and IS (II), respectively. (D) Blank plasma sample of PF group; (E) blank spiked with PF (I) and carbamazepine (II); (F) samples after $30 \mathrm{~min}$ of administration PF (I) and carbamazepine (II), respectively. Figure S2. Chromatograms of typical tissues. (A) Blank tissues sample of TP group; (B) blank spiked with TP (I) and carbamazepine (II); (C) samples after $30 \mathrm{~min}$ of administration of TP (I) and carbamazepine (II), respectively. (D) Blank tissues sample of PF group (E) blank spiked with PF (I) and carbamazepine (II); (F) samples after $30 \mathrm{~min}$ of administration of $\mathrm{PF}(\mathrm{I})$ and carbamazepine (II), respectively. Table S1: recovery and matrix effect for the analysis of $\mathrm{TP}$ and PF in plasma $(n=6)$. Table S2: recovery and matrix effect of TP in tissues $(n=5)$. Table S3: recovery and matrix effect of PF in tissues $(n=5)$. Table S4: stability of TP in plasma $(n=6)$. Table S5: stability of PF in plasma $(n=6)$. Table S6: stability of TP in tissues. Table S7: stability of PF in tissues. (Supplementary Materials)

\section{References}

[1] L. Na, L. MingYao, and L. Ye, "Research progress of triptolide in vivo and in vitro," Strait Pharmaceutical Journal, vol. 27, no. 12, pp. 99-101, 2015.

[2] Z. Di, L. Xue, P. Sheban, and Z. Honghua, "Recent research advances on triptolide," Chinese Wild Plant Resources, vol. 33, no. 3, pp. 27-31, 2014.

[3] T. Tai, J. Zhenzhou, H. Xin, J. Jinzi, and Z. Luyong, "Advance in pharmacokinetics of triptolide," Pharmaceutical and Clinical Research, vol. 20, no. 3, pp. 229-235, 2012.

[4] L. XiaoJiaoyang, J. Zhenzhou, and Z. Luyong, "Triptolide: progress on research in pharmacodynamics and toxicology," Journal of Ethnopharmacology, vol. 155, no. 1, pp. 67-69, 2014.

[5] G. Yongmei, T. Ling, X. Fang, C. Lihua, Z. Yimin, and J. Chen, "Prescription rules of preparations containing Tripterygium wilfordii Hook.f.against," Chinese Journal of Hospital Pharmacy, vol. 38, no. 1, pp. 64-68, 2018.

[6] T. Ling, G. Yongmei, C. Lihua, X. Fang, and J. Chen, "Research progress on detoxicity by tripterygii radixet rhizoma compatibility," Chinese Journal of Experimental Traditional Medical Formulae, vol. 24, no. 4, pp. 229-234, 2018.

[7] J. Zhang, Y. Guan, H. Liangfei et al., "Influence of a combination of triptolide and ferulic acid on the activities of CYP450 enzymes and oxidative stress in $\mathrm{HaCaT}$ cells," 
Experimental and Therapeutic Medicine, vol. 20, no. 6, p. 157, 2020.

[8] X. Fang, "Effect of triptolide combined with paeoniflorin on the toxicity of L-02 cell," Practical Clinical Journal of Integrated Traditional Chinese and Western Medicine, vol. 24, no. 4, pp. 156-157, 2020.

[9] W. Jian, "Clinical observation of tripterygium wilfordii polyglycosidium combined with total glucosides of paeony for rheumatoid arthritis," Journal of New Chinese Medicine, vol. 50, no. 6, pp. 118-120, 2018.

[10] B. DanYan, L. Qin, Z. Hong et al., "Clinical efficacy of tripterygium glycosides combined with methotrexate in the treatment of rheumatoid arthritis," The Chinese Journal of Clinical Pharmacology, vol. 32, no. 10, pp. 880-882, 2016.

[11] L. Yan, X. Tong, L. Heng, and Z. XuePing, "Study on the theory of "heterogeneous restriction" from the material base of detoxicity effect of the compound prescription of Chinese herbal medicine," Journal of Nanjing University of Traditional Chinese Medicine, vol. 32, no. 1, pp. 97-100, 2016.

[12] C. KaiLi, Y. JianFeng, S. Lan, S. Wen, and Z. WenJing, "Effect of tripterygium glycosides on pharmacokinetics of total glucosides of paeony in rats in vivo," Journal of Jinggangshan University (Natural Science), vol. 38, no. 1, pp. 88-92, 2017.

[13] L. Jiamin, L. Nan, X. Hairong, and D. Xiaoyan, "Research progress of in vitro release, transdermal properties and in vivo pharmacokinetics of transdermal drug delivery systems," Journal of Logistics University of CAPF (Medical Sciences), vol. 22, no. 12, pp. 1137-1140, 2013.

[14] G. Yongmei, Y. Zhihong, H. Lihua et al., "Pharmacokinetics of triptolide in Triptergium wilfordii microemulsion gel," China Journal of Chinese Materia Medica, vol. 36, no. 2, pp. 216-219, 2011.

[15] Y. Yating, Z. Weifeng, C. Lihua, J. Chen, Y. Kaili, and G. Yongmei, "Preparation of Triptolide microemulsion-based gel and investigation of its in vitro percutaneous permeability," Chinese Journal of Hospital Pharmacy, vol. 36, no. 13, pp. 1087-1091, 2016.

[16] G. Yongmei, Design and Evaluation of Tripterygium Wilfordii Microemulsion Gel Transdermal Drug Delivery System, Chengdu University of TCM, Chengdu, China, 2018.

[17] Y. Xinlan, C. Feng, and C. Yunzhi, "Application progress of TGP in autoimmune diseases," Acta Chinese Medicine and Pharmacology, vol. 47, no. 1, pp. 127-130, 2019.

[18] K. Xue and S. Dongmei, "Mechanism of applying paeoniflorin in dermatology," Chinese Journal of Dermatovenereology of Integrated Traditional and Western Medicine, vol. 17, no. 5, pp. 473-476, 2018.

[19] L. Liu, Z. Jiang, J. Liu et al., "Sex differences in subacute toxicity and hepatic microsomal metabolism of triptolide in rats," Toxicology, vol. 271, no. 1-2, pp. 57-63, 2010.

[20] E. Tur, "Physiology of the skin-differences between women and men," Clinics in Dermatology, vol. 15, no. 1, pp. 5-16, 1997.

[21] W. Jiangyuan, Study on the Pharmacokinetics of Triptolide and its Effect to Ovary Tumor Cells, Wuhan University, Wuhan, China, 2005. 